\title{
Editors' introduction to the special issue on the sociology of digital technology
}

\author{
Sharon Zukin ${ }^{1} \cdot$ John Torpey ${ }^{1}$
}

Accepted: 9 July 2020 / Published online: 8 September 2020/

(C) Springer Nature B.V. 2020

\begin{abstract}
An increasing number of sociologists today are examining the social production of digital technology. Although younger researchers may be digital natives and write from "within the algorithm," and older sociologists may begin by trying to define terms and concepts that have become commonplace in the tech "space," all share the goal of unpacking the "black box" of computer software by analyzing how, where, and by whom it is developed and asking who benefits most by its use. Some of the articles in this special issue of Theory and Society focus on questions of connectivity, privacy, and equity in light of classical sociology's concern with the state, the self, knowledge, and power; others look critically at forms of inequality in the operations of specific platforms, algorithms, urban tech ecosystems, and coworking spaces.
\end{abstract}

Keywords Algorithms · Digital sociology · Digital technology · Economic sociology · Social studies of science and technology $\cdot$ Technology and power

With this special issue on digital technology, Theory and Society enters a new and enormously important area of sociological inquiry, one that demands not only intellectual rigor but also social engagement and self-examination. Although this is not an easy set of tasks, it speaks to both the journal's origins and its mission. The harder part is grasping the subject's complexity. Writing about digital technology is like catching water in your hand: the form is fluid, the situation changes quickly, and, aside from certain basic elements, the existence of the thing that you are trying to explain reflects processes and interactions that go far beyond the immediate human actor.

Sharon Zukin

szukin@gc.cuny.edu

John Torpey

jtorpey@gc.cuny.edu

1 PhD Program in Sociology, CUNY Graduate Center, 365 Fifth Avenue, New York, NY 10016, USA 
For some sociologists, especially if they are older, digital technology remains a black box of mathematical formulas (algorithms) and mysterious languages and logics (computer codes) that are somehow combined to create software (programs, apps) that allows us to do things as users, workers, and consumers. We navigate on Google Maps, share photos on Facebook and Instagram, stream films on Netflix, and arrange for car rides on Uber. The technology that has made these activities so convenient-by reducing the "friction" of direct human involvement - has become as much a part of daily life as our cell phones. Corporate names like Google and Zoom have been transformed into generic nouns and verbs, becoming the Kleenex and Band-Aids of today. Yet, trying to capture digital technology in a single analytic frame challenges existing concepts, methods, and fields.

The field called social studies of science and technology that emerged in the midtwentieth century offers some direction. Identified, in the United States, with the work of the sociologist Robert K. Merton and the philosopher of science Thomas Kuhn, the field began by exploring the social and cultural conditions in which new ideas emerge and become paradigms, displacing hegemonic knowledge regimes. Other researchers have directed their attention to elite networks of the knowledge professions, legal frameworks of contracts and intellectual property rights, and the financial and political capacity of states and capital to support technological innovation. More recently, sociologists, anthropologists, and historians have looked at the social construction of technological systems through constantly changing interactions between human and nonhuman actors, including people, computers, organizations, and ideologies, which are not necessarily ranked in any order of importance. This approach differs from both classical sociological frameworks of the nineteenth and early twentieth centuries, with their focus on states, social classes, and bureaucracies, and a postmodern emphasis on more diffuse though no less institutionalized systems of power, knowledge, and control.

Since the early 2010s, when the software engineer and venture capitalist Marc Andreessen (2011) famously declared that "software is eating the world," technological innovation has become more centralized in the hands of larger and richer corporations while control of technology is increasingly contested by private citizens and states. Who has the right to own the data generated by private users of digital platforms? What happens when software is used to monitor people's movements, persuade them to buy things, or evaluate their potential to commit crimes? During the past few years, and with sudden drama during the Covid-19 pandemic, we all became aware that the buildup of digital surveillance transcends local and even national scale. The technology, and the companies that make, deploy, and profit from it, are everywhere.

The toolbox of digital technology contains more than mechanisms of control. Digital tools shape strategies of representation. Facial recognition software often misidentifies people of color. Some software languages perpetuate racist and gender stereotypes. Commercial algorithms used by hospitals to decide which patients should get more intensive care are biased against black patients (Obermeyer et al. 2019). Yet, the same digital platform can be used to represent different interests and mobilize diametrically opposed constituencies. Twitter serves both \#realDonald Trump and \#Black Lives Matter.

We confront, then, as both scholars and users, multiple forms, uses, and meanings of digital technology. Any attempt to explain its social production must inevitably focus 
on a limited range of examples, conditions, and sites. For some writers in the sociological tradition, tech is a new kind of knowledge; for others, it is a new means of social control. Although the promise of democratic access to the World Wide Web has been overshadowed by its uses for commercial profit, it is important to examine how and why resistance to Big Tech companies emerges from forces as disparate as the European Union and the US Senate; social movements in New York, Toronto, and Berlin; and, increasingly, the companies' own employees, from engineering teams at Google to Amazon warehouse workers.

With a deep appreciation of both the complexity of digital technology and our moral responsibility to struggle with its social effects, this issue of Theory and Society presents ten articles by sociologists who are devising new approaches to explore different aspects of digital technology on different research sites. Loosely speaking, the articles fall into three broad categories: concepts, mechanisms, and places. The first three articles, on concepts, connect current issues such as connectivity and privacy to sociology's classical core concerns, beginning with the self, the state, power, and inequality. The next four articles, on mechanisms, look closely at core products of digital technology-platforms and algorithms - to document their effects on different groups of users and workers, in different organizational milieux, and with different kinds of cultural biases. The final three articles, on places, focus on the city as simultaneously a platform, a market, and a regulator of digital technology, as well as a material space of tech work. Although all three articles take New York City as their research site, they focus on different parts of the city's tech ecosystem, showing that the socio-spatial structures of a digital economy are interwoven with state institutions, cultural forms, and changing expectations of workers and work.

The authors of the articles in this issue represent diverse generations, have slightly different educational backgrounds, and use varied methods. Some of them are digital natives and write from "within the algorithm"; others clearly stand outside it. They do not yet define a coherent field, but they do not fit neatly into existing disciplinary silos or subfields of sociology. Nonetheless, individually and together, they create a nuanced though still tentative understanding of what digital technology does, who profits from it, and what that suggests about social change. Although these authors cast a wide net, there are many more topics and regions of the world that should and must be considered if we are to understand the tech transformation of the planet.

With these articles, Theory and Society issues both a provocation and an invitation. We open the journal's doors to social research that engages with digital technology in a multitude of ways that change both theory and society. And we reaffirm the journal's interest since its founding in sociological studies of economic organization, culture, and power.

\section{References}

Andreessen, M. (2011). Why software is eating the world. https://www.wsj. com/articles/SB10001424053111903480904576512250915629460, 20 August. Accessed 6 July 2020.

Obermeyer, Z., Powers, B., Vogeli, C., \& Mullainathan, S. (2019). Dissecting racial bias in an algorithm used to manage the health of populations. https://science.sciencemag.org/content/366/6464/447, 25 October. Accessed 20 June 2020. 
Publisher's note Springer Nature remains neutral with regard to jurisdictional claims in published maps and institutional affiliations.

Sharon Zukin is professor emerita of sociology at Brooklyn College and the Graduate Center, City University of New York; her work connects urban culture and economic change.

John Torpey is Presidential Professor of Sociology and History and Director of the Ralph Bunche Institute for International Studies at the Graduate Center, City University of New York; he specializes in comparative historical sociology and research on the contemporary state, religion, and politics. 